\title{
AMENDMENTS
}

\section{Author Correction: Convalescent plasma for hospitalized patients with COVID-19: an open-label, randomized controlled trial}

Philippe Bégin (D), Jeannie Callum (D), Erin Jamula, Richard Cook, Nancy M. Heddle, Alan Tinmouth, Michelle P. Zeller, Guillaume Beaudoin-Bussières, Luiz Amorim, Renée Bazin, Kent Cadogan Loftsgard, Richard Carl, Michaël Chassé, Melissa M. Cushing, Nick Daneman, Dana V. Devine, Jeannot Dumaresq, Dean A. Fergusson, Caroline Gabe, Marshall J. Glesby ID, Na Li, Yang Liu, Allison McGeer, Nancy Robitaille, Bruce S. Sachais, Damon C. Scales, Lisa Schwartz (D), Nadine Shehata, Alexis F. Turgeon (D), Heidi Wood, Ryan Zarychanski, Andrés Finzi, the CONCOR-1 Study Group* and Donald M. Arnold (D)

Correction to: Nature Medicine https://doi.org/10.1038/s41591-021-01488-2, published online 9 September 2021.

In the version of this Article initially published, there was an omission in the member list for the CONCOR-1 Study Group. Valérie Arsenault (Héma-Québec, Montreal, Quebec, Canada) has now been included in the CONCOR-1 Study Group in the online version of the article.

${ }^{*}$ A list of authors and their affiliations appears online.

Open Access This article is licensed under a Creative Commons Attribution 4.0 International License, which permits use, sharing, adaptation, distribution and
reproduction in any medium or format, as long as you give appropriate credit to the original author(s) and the source, provide a link to the Creative Commons
license, and indicate if changes were made. The images or other third party material in this article are included in the article's Creative Commons license, unless
indicated otherwise in a credit line to the material. If material is not included in the article's Creative Commons license and your intended use is not permitted by statutory regula-
tion or exceeds the permitted use, you will need to obtain permission directly from the copyright holder. To view a copy of this license, visit http://creativecommons.org/licenses/
by/4.0/.
Published online: 12 January 2022
https://doi.org/10.1038/s41591-021-01667-1
(C) The Author(s) 2022

\section{Author Correction: The impact of school opening model on SARS-CoV-2 community incidence and mortality}

Zeynep Ertem, Elissa M. Schechter-Perkins (D), Emily Oster, Polly van den Berg, Isabella Epshtein,

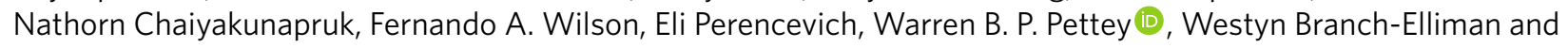
Richard E. Nelson

Correction to: Nature Medicine https://doi.org/10.1038/s41591-021-01563-8, published online 27 October 2021.

In the version of this Article initially published, a versioning error led to a mistake in the third paragraph of the Discussion. In the text now reading "In our dataset, the most extreme and sustained increase in SARS-CoV-2 cases associated with school opening was in the South, where school opening was associated with a weekly increase in cases ranging from 9.8 to 21.3 per 100,000 people," the range initially reported was "7.8 to 18.9 per 100,000 ." The results presented in the text and figures are unaffected.

The change has been made to the online version of the Article.

Published online: 12 January 2022

https://doi.org/10.1038/s41591-021-01669-z

This is a U.S. government work and not under copyright protection in the U.S.; foreign copyright protection may apply 2022 